LWSA

Local Wisdom, Social, and Arts

PAPER - OPEN ACCESS

\title{
Leksikostatistik Bahasa Karo dan Bahasa Gayo
}

$\begin{array}{ll}\text { Author } & : \text { Dardanila Dardanila } \\ \text { DOI } & : 10.32734 / \text { lwsa.v1i1.161 } \\ \text { Electronic ISSN } & : 2654-7058 \\ \text { Print ISSN } & : 2654-7066\end{array}$

Volume 1 Issue 1 - 2018 TALENTA Conference Series: Local Wisdom, Social and Arts

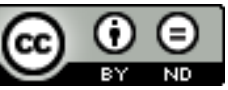

This work is licensed under a Creative Commons Attribution-NoDerivatives 4.0 International License.

Published under licence by TALENTA Publisher, Universitas Sumatera Utara
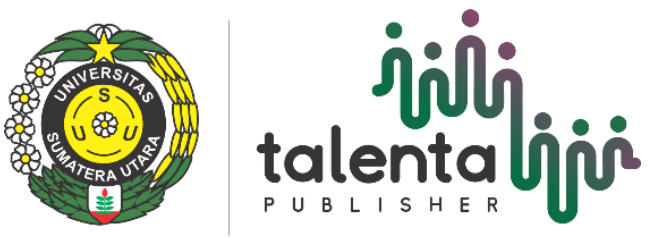


\title{
Leksikostatistik Bahasa Karo dan Bahasa Gayo
}

\author{
Dardanila $^{a}$ \\ ${ }^{a}$ Fakultas Ilmu Budaya, Universitas Sumatera Utara, Medan-20155 \\ dardanila14@gmail.com
}

\begin{abstract}
Abstrak
Kertas kerja ini merupakan laporan hasil penelitian mengenai leksikostatistik bahasa Karo dan bahasa Gayo. Metode penelitian yang digunakan dalam penelitian ini adalah metode komparatif dengan teknik leksikostatistik. Hasil penelitian ini menunjukkan secara kuantitatif diperlihatkan bahwa relasi kekerabatan yang erat dipertalikan pada persentase kognat sebesar 43,5\% tingkat kekerabatan antara bahasa Karo dengan bahasa Gayo. Perhitungan waktu pisah bahasa Karo dan bahasa Gayo adalah 1,926 ribuan tahun yang lalu. Atau, dengan kata lain, perhitungan waktu pisah bahasa Karo dan bahasa Gayo dapat dinyatakan satu bahasa tunggal sekitar 1,926 ribuan tahun yang lalu.
\end{abstract}

Kata Kunci: Leksikostatistik; Waktu Pisah; bahasa Karo; bahasa Gayo

\section{Pendahuluan}

Leksikostatistik adalah suatu teknik yang memungkinkan kita untuk menentukan tingkat hubungan di antara dua buah bahasa, dengan menggunakan cara yang paling mudah, yaitu dengan membandingkan kosa kata pada bahasabahasa tersebut yang kemudian dapat dilihat dan ditentukan tingkat kesamaan di antara kosa kata kedua bahasa, Dengan demikian, sejauh mana hubungan kekerabatan satu bahasa dengan bahasa lainnya dapat diketahui.

Semua bahasa di dunia khususnya di kawasan tertentu memiliki tingkat kekerabatan termasuk bahasa-bahasa di Aceh dan di Sumatera Utara. Tingkat kekerabatan suatu bahasa didasarkan pada kemiripan bentuk dan makna leksikal karena warisan langsung. Hal ini sejalan dengan yang dikemukakan oleh Keraf (1984:37) bahwa yang menjadi dasar dalam menetapkan tingkat kekerabatan adalah kemiripan bentuk dan makna karena warisan langsung. Bentuk-bentuk kata yang sama antara berbagai bahasa dengan makna yang sama atau mirip diperkuat lagi dengan kesamaan-kesamaan unsur tata bahasa, akan mendorong kita mengambil kesimpulan bahwa bahasa-bahasa tersebut diturunkan dari satu Protobahasa yang sama. Dalam ensiklopedi bahasa Indonesia disebutkan bahwa kata-kata kerabat adalah kata-kata yang masih diturunkan dari sumber yang sama. (www.wikipedia.bahasa_indonesia ensiklopedia diakses 06122010).

Pada penelitian ini, kedua bahasa yang diteliti yaitu bahasa Karo dan bahasa Gayo yang menjadi sasaran dalam penelitian ini akan dibuktikan tingkat kekerabatan kedua bahasa. Kemudian dilanjutkan dengan menghitung waktu pisah kedua bahasa. Penelitian ini sangat penting untuk pelestarian bahasa daerah Karo dan bahasa daerah Gayo. 


\section{Pembahasan}

Penelitian ini dikaji dengan menggunakan metode komparatif. Metode komparatif yaitu membandingkan 200 kosakata dasar Swadesh yang dialihbahasakan dalam bahasa Karodan bahasa Gayo untuk mendapatkan data yang berkerabat dianalisis secara kuantitatif dengan menggunakan teknik leksikostatistik. Dengan teknik ini dapat diperoleh jumlah persentase kognat masing-masing bahasa.

\begin{tabular}{|c|c|c|c|}
\hline $\begin{array}{l}\text { No.U/ } \\
\text { Data }\end{array}$ & BK & BG & Glos \\
\hline $1 / 3$ & urat & uyət & $=$ akar' $^{6}$ \\
\hline $2 / 4$ & anak & anak & $=$ anak $^{\star}$ \\
\hline $3 / 11$ & əmbun əmun & $=$ awan` $^{\circ}$ & \\
\hline $4 / 14$ & bagi & bagi & =bagi“ \\
\hline $5 / 15$ & barəh & barah & $=$ bisul $^{\circ}$ \\
\hline $6 / 19$ & bata* & bata ${ }^{2}$ & batang' \\
\hline $7 / 20$ & batu & atu & _batu' \\
\hline $8 / 25$ & mbərat & $=$ berat $^{\star}$ & \\
\hline $9 / 26$ & taya $a^{\circ}$ & gula & baring' \\
\hline $10 / 30$ & dalan & ralan & jalan` \\
\hline $11 / 32$ & nipi & nipi & $=$ mimpi $^{`}$ \\
\hline $12 / 33$ & kəsah & kəsah & $=$ napas $^{6}$ \\
\hline $13 / 37$ & binta $^{2}$ & binta ${ }^{\circ}$ & bintang ${ }^{6}$ \\
\hline $14 / 38$ & buah & uah & =buah' \\
\hline $15 / 39$ & bulan & ulən & $=$ bulan' \\
\hline $16 / 41$ & $\mathrm{bu}^{\stackrel{2}{*} \mathrm{a}}$ & $\mathrm{bu}^{\circ} \mathrm{\circ}$ & =bunga' \\
\hline $17 / 46$ & ras & rum & =dengan' \\
\hline $18 / 49$ & rəh & geh & =datang' \\
\hline $19 / 50$ & bulu & ulu & =daun' \\
\hline $20 / 52$ & $\mathrm{i}$ & $\mathrm{i}$ & $=\mathrm{di}^{6}$ \\
\hline $21 / 51$ & abu & awu & _debu“ \\
\hline $22 / 54$ & təruh & tuyuh & =bawah' \\
\hline $23 / 55$ & bas & was & =dalam' \\
\hline $24 / 59$ & dua & roa & $=\mathrm{dua}^{6}$ \\
\hline $25 / 60$ & kundul & kunul & $=$ duduk $^{6}$ \\
\hline $26 / 62$ & әmpat & opat & =empat ${ }^{`}$ \\
\hline $27 / 63$ & $\partial^{\circ} \mathrm{ko}$ & ko & engkau“ \\
\hline $28 / 64$ & sira & sira & _garam ${ }^{6}$ \\
\hline $29 / 65$ & ipən & ipon & =gigi‘ \\
\hline $30 / 66$ & $1 \partial^{2}$ gur & guntur & \\
\hline $31 / 68$ & ate & ate & hati' \\
\hline $32 / 69$ & igu $^{*}$ & iyu ${ }^{2}$ & =hidung ${ }^{6}$ \\
\hline $33 / 73$ & kira & kirə & =hitung' \\
\hline $34 / 74$ & udan & urən & =hujan' \\
\hline $35 / 82$ & janto & jantu & jantung' \\
\hline $36 / 83$ & jarum & jarum & jarum \\
\hline $37 / 85$ & jait & jit & jahit‘ \\
\hline $38 / 87$ & kambi $\mathrm{kami}^{*}$ & =kambing“ & \\
\hline $39 / 90$ & kəmuhən & kuən & = kanan' \\
\hline
\end{tabular}




\begin{tabular}{|c|c|c|c|}
\hline $40 / 92$ & kayu & kayu & kayu“ \\
\hline $41 / 95$ & kəri ${ }^{\circ}$ & kərah & =kering' \\
\hline $42 / 96$ & kilap & kilət & _kilat‘ \\
\hline $43 / 98$ & ita & kitə & =kita“ \\
\hline $44 / 100$ & kulit & kulit & $=$ kulit $^{\star}$ \\
\hline $45 / 102$ & kutu & kutu & =kutu' \\
\hline $46 / 103$ & lawah-lawah ləlawah & & laba-laba' \\
\hline $47 / 106$ & lait & lait & langit' \\
\hline $48 / 110$ & lima & $\operatorname{limə}$ & =lima‘ \\
\hline $49 / 111$ & dilah & delah & lidah' \\
\hline $50 / 112$ & $\operatorname{man}$ & $m a^{\circ}$ an & _makan' \\
\hline $51 / 115$ & mata & mata & mata' \\
\hline $52 / 116$ & mate & mate & _mati ${ }^{\prime}$ \\
\hline $53 / 117$ & lipat & lipot & lipat' \\
\hline $54 / 120$ & $\operatorname{miri}^{*}$ & mere ${ }^{2}$ & miring ${ }^{6}$ \\
\hline $55 / 121$ & tutu ${ }^{\circ}$ & tutu & _bakar‘ \\
\hline $56 / 122$ & naka & taka & =belah` \\
\hline $57 / 125$ & mbunuh & unuh & =bunuh' \\
\hline $58 / 128$ & pilih & pilih & _pilih‘ \\
\hline \multicolumn{2}{|c|}{ 59/129 kərət } & kərat & _potong' \\
\hline \multicolumn{2}{|c|}{ 60/130 pəkpək $\quad$ pəpok } & _pukul' & \\
\hline \multicolumn{2}{|c|}{$61 / 131$ tanəm } & tanom & $=$ tanam $^{`}$ \\
\hline \multicolumn{2}{|c|}{$62 / 138$ tuktuk } & totok & $=$ ketuk $^{6}$ \\
\hline 63/142 & ikət & ikot & _ikat‘ \\
\hline \multicolumn{2}{|c|}{ 64/148 timur } & timur & =timur ${ }^{6}$ \\
\hline \multicolumn{2}{|c|}{$65 / 151$ minəm minum } & $=$ minum ${ }^{\prime}$ & \\
\hline \multicolumn{2}{|c|}{$66 / 152$ babah } & awah & $=$ mulut ${ }^{‘}$ \\
\hline \multicolumn{2}{|c|}{ 67/155 gəlar } & gərəl & nama' \\
\hline \multicolumn{2}{|c|}{ 68/157 jəlma } & jəma & =orang' \\
\hline \multicolumn{2}{|c|}{ 69/163 dibəru } & bəbər & _perempuan“ \\
\hline $70 / 165$ & pitu & pitu & ${ }^{\text {tujuh }}{ }^{\prime}$ \\
\hline \multicolumn{2}{|c|}{$71 / 167$ buk } & wuk & $=$ rambut ${ }^{6}$ \\
\hline \multicolumn{2}{|c|}{$72 / 168$ rumah } & umah & _rumah' \\
\hline $73 / 170$ & sakit & sakit & _sakit" \\
\hline $74 / 171$ & sada & sara & _satu“ \\
\hline \multicolumn{2}{|c|}{ 75/172 aku } & aku & $=$ saya ${ }^{\prime}$ \\
\hline \multicolumn{2}{|c|}{ 76/174 cəbuni } & mbunyi‘ & \\
\hline \multicolumn{2}{|c|}{$77 / 180$ tahun } & tun & $=$ tahun' $^{6}$ \\
\hline $78 / 183$ & nali & tali & $=$ tali $^{`}$ \\
\hline \multicolumn{2}{|c|}{$79 / 184$ tanəh } & tanoh & $=\operatorname{tanah}^{\prime}$ \\
\hline \multicolumn{2}{|c|}{$80 / 189 \mathrm{kaba}^{\circ}$} & tərba ${ }^{2}$ & terbang' \\
\hline $81 / 191$ & janji & janji & janji` \\
\hline $82 / 193$ & təlu & tulu & =tiga' \\
\hline \multicolumn{2}{|c|}{ 83/196 mətua } & tuə & tua' \\
\hline $84 / 197$ & tulan & tulən & =tulang' \\
\hline \multicolumn{2}{|c|}{ 85/198 mantul } & tumpul & $=$ tumpul' \\
\hline $86 / 199$ & nipe & lipe & _ular \\
\hline
\end{tabular}


Langkah berikutnya adalah menghitung tingkat persentase kekerabatan bahasa yang dibandingkan, dengan rumus yang dikemukakan oleh Keraf, (1984:172).

$$
\mathrm{C}=\underline{\mathrm{K}} \times 100 \%
$$

$\mathrm{C}=$ kognates atau kata yang berkerabat

$\mathrm{K}=$ jumlah kosakata berkerabat

$\mathrm{G}=$ jumlah glos

Kemudian menghitung waktu pisah kedua bahasa tersebut dengan cara menghitung mempergunakan rumus yang dikemukakan oleh (Crowley, 1992:178; Keraf, 1984:130).

$$
\mathrm{t}=\underline{\log \mathrm{c}}
$$

$2 \log r$

$\mathrm{t}=$ waktu perpisahan dalam ribuan (melenium) tahun yang lalu

$\mathrm{r}=$ retensi atau persentase konstan dalam 1000, atau disebut juga indeks

$\mathrm{c}=$ persentase kerabat

$\log =$ logaritma dari

Rumus di atas dapat diselesaikan dengan melalui tahapan-tahapan:

(1) Langkah pertama, cari logaritma c dan $r$ dalam daftar logaritma

(2) Kalikan logaritma $r$ dengan 2

(3) Hasil logaritma c dibagi dengan hasil dari (2)

(4) Hasil dari pembagian (3) menunjukkan waktu pisah dalam satuan ribuan tahun. Hasil terakhir ini dapat diubah menjadi tahun biasa setelah dikalikan dengan 1000 tahun. Karena perpisahan itu tidak terjadi dalam 1 tahun tertentu, lebih baik dipertahankan dalam bentuk satuan ribuan tahun (melenium).

\subsection{Leksikostatistik Bahasa Karo dan Bahasa Gayo}

Bahasa Karo dan bahasa Gayo merupakan dua bahasa sekerabat yang erat relasi historisnya. Dalam kesempatan ini akan diuraikan analisis kuantitatif hubungan antara bahasa Karo dengan bahasa Gayo mendahului analisis kualitatif. Tujuan analisis kuantitatif adalah untuk menemukan gambaran sekilas tentang relasi kekerabatan antara bahasa yang dibandingkan dalam rangka menetapkan diagram pohon silsilah kekerabatan secara kuantitatif. Selain itu, berdasarkan hasil yang diperoleh pada tahap itu ditempuh langkah kerja selanjutnya berupa penganalisisan kualitatif

Dari dua ratus kata dasar Swadesh (Revisi Blust, 1980 ), ditemukan 87 kata yang berkerabat antara bahasa Karo dengan bahasa Gayo. Dengan demikian dapat dihitung tingkat kekerabatan antara keduanya dengan menggunakan perhitungan leksikostatistik:

Tingkat kekerabatan:

$$
\mathrm{C}=\underline{\mathrm{K}} \times 100 \%
$$

$\mathrm{C}=$ cognates atau kata yang berkerabat

$\mathrm{K}=$ jumlah kosa kata berkerabat

$\mathrm{G}=$ jumlah glos

$=\underline{\mathrm{K}} \times 100 \%=8 \underline{7} \times 100 \%=43,5 \%$

200 200

Dengan menggunakan acuan dari Crowley dan Keraf, bahasa Karo dengan bahasa Gayo berada dalam kategori satu rumpun atau stock. 


\subsubsection{Grafik Persentase Kekerabatan Bahasa Karo dan Bahasa Gayo}

Pada tahap ini dapat ditetapkan persentase kognat antara bahasa sekerabat yang dibandingkan dapat dilihat dalam grafik berikut.

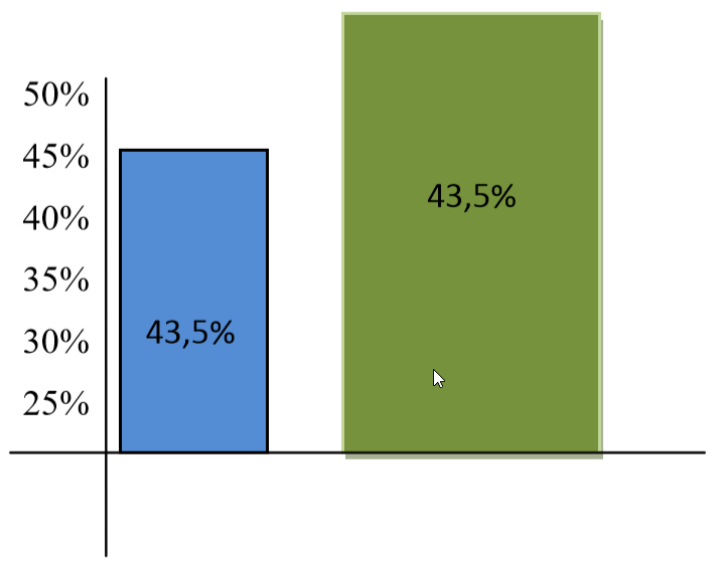

\subsubsection{Penjelasan Grafik}

Grafik di atas menunjukkan bahwa persentase kata kerabat dari bahasa Karo dan bahasa Gayo 43,5\%. Berdasarkan perbandingan persentase, dapat ditarik kesimpulan bahwa antara bahasa Karo dengan bahasa Gayo memilki tingkat kekerabatan yang dekat.

Setelah mengetahui persentase kata kerabat dari bahasa yang dibandingkan, langkah selanjutnya menyusun grafik silsilah kekerabatan (stammbaum) dari bahasa Karo dan bahasa Gayo.

\subsubsection{Grafik Silsilah Kekerabatan Bahasa Karo dan Bahasa Gayo}

\begin{tabular}{ccc}
$\begin{array}{c}\text { Persentase } \\
\text { Kognat }\end{array}$ & Garis Silsilah Kekerabatan BK dan BG & \\
\hline 25 & \\
30 & \\
35 & Keluarga \\
40 & (famili) \\
45 & $43,5 \%-73 \%$ \\
50 & \\
55 & & \\
60 & & \\
65 & & \\
70 & & \\
75 & & \\
80 & BG & \\
85 & & \\
100 & BK & \\
BK dan & & \\
BG & & \\
\hline
\end{tabular}

Menurut Swadesh (1955:101) apabila hubungan diantara bahasa itu menunjukkan persentase kognat dari $36 \%$ sampai dengan $80 \%$ maka angka persentase itu menunjukkan hubungan sebagai hubungan keluarga bahasa (language 
offamily). Jika kriteria leksikostatistik itu diterapkan disini, maka rentang persentase antara bahasa yang dibandingkan yaitu bahasa Karo dan bahasa Gayo angka persentasenya sebesar 43,5\% adalah sebagai hubungan keluarga bahasa (language of family). Dengan demikian, hasil yang dicapai dalam analisis leksikostatistik ini dapat menjadi hipotesis kerja bagi tahap penelitian berikutnya, yaitu analisis kualitatif.

\subsection{Waktu Pisah Bahasa Karo dengan Bahasa Gayo}

$\mathrm{t}=\frac{\log }{2 \log }$

$\mathrm{t}=$ waktu perpisahan dalam ribuan (melenium) tahun yang lalu

$\mathrm{r}=$ retensi atau prosentase konstan dalam 1000, atau disebut juga indeks

$\mathrm{C}=$ prosentase kerabat

Log = logaritma dari

$$
\begin{aligned}
& \frac{=\log }{2 \log } \\
& \begin{aligned}
& \log 43,5 \% \\
& =2 \log 80,5 \% \\
& =-0,632 \\
= & =-0,188 \\
&
\end{aligned}
\end{aligned}
$$

Perhitungan waktu pisah bahasa Karo dengan bahasa Gayo adalah 1,926 ribuan tahun yang lalu. Atau, dengan kata lain, perhitungan waktu pisah bahasa Karo dan bahasa Gayo dapat dinyatakan:

1. Bahasa Karo dengan bahasa Gayo diperhitungkan merupakan satu bahasa tunggal sekitar 1,926 ribuan tahun yang lalu,

2. Bahasa Karo dengan bahasa Gayo diperkirakan mulai berpisah dari suatu bahasa proto kira-kira abad III Sebelum Masehi.

\section{Penutup}

Berdasarkan analisis dapat ditarik kesimpulan sebagai berikut:

\section{1) Tingkat Kekerabatan}

Kedua bahasa yang telah diteliti yaitu bahasa Karo dan bahasa Gayo telah dibuktikan hubungannya sebagai bahasa berkerabat. Secara kuantitatif diperlihatkan bahwa relasi kekerabatan antara bahasa Karo dengan bahasa Gayo 43,5\% dari 87 kata berkerabat, dalam klasifikasi leksikostatistik kekerabatan pada tingkat 43,5\% disebut sebagai status keluarga (family).

\section{2) Perhitungan Waktu Pisah Bahasa}

Perhitungan waktu pisah bahasa Karo dan bahasa Gayo adalah 1,926 ribuan tahun yang lalu. Atau, dengan kata lain, perhitungan waktu pisah bahasa Karo dan bahasa Gayo dapat dinyatakan satu bahasa tunggal sekitar 1,926 ribuan tahun yang lalu.

\section{Daftar Pustaka}

[1] A. K, Baihaqi dan Abdul Gani Asyik dkk. 1981. Bahasa Gayo. Jakarta: Pusat Pembinaan dan Pengembangan Bahasa Depdikbud.

[2] Bellywood, Peter. 2000. Prasejarah Kepulauan Indo-Malaysia. Jakarta: Gramedia. 
[3] Blust, R.A. 2013. The Austronesian Languages.Australia:Asia-Pasific Linguistics.

[4] Budasi, I Gede. 2010. Status Kekerabatan Isolek Laura dan Gaura pada Kelompok Bahasa Sunda di NTT. Makalah Seminar Internasional V.

[5] Denpasar: Universitas Udayana.

[6] Bynon, T. 1979. Historical Linguistics. Cambridge: Cambridge University Press, Port Moresby: University of The Papua New Guinea Press.

[7] Crowly, Terry. 1992. An Introduction to Historical Linguistics. Oxford: Oxford University Press. Dardanila. 2005. —Bunyi Vokal Bahasa Gayo Dialek Gayo Lut”. Dalam Jurnal Ilmu-ilmu Bahasa dan sastra _LOGAT\| Vol.1 No.1, 1-5.

[8] Dardanila. 2016. —Kekerabatan Bahasa Karo, Bahasa Alas dan Bahasa Gayoll. Disertasi S-3 Universitas Sumatera Utara. Medan

[9] Eades, Domenyk. 2005. A Grammar of Gayo: A Language of Aceh, Sumatera, Australia. Pacipic Linguistics Researtch School of Pasipic and Asian Studies.

[10] Fernandez, Inyo Yos. 1996. Relasi Historis Kekerabatan Bahasa Flores : Kajian Linguistik Historis Komparatif terhadap Sembilan Bahasa di Flores. Flores: Nusa Indah.

[11] Hock, Hans Henry. 1988. Principles of Historical Linguistics. Berlin-New York-Amsterdam: Mouton the Gruyter.

[12] Keraf, Gorys. 1996. Linguistik Bandingan Historis. Jakarta: Gramedia Pustaka Umum.

[13] Mbete, Aron Meko. 2002. Metode Linguistic Diakronis. Denpasar: Universitas Udayana.

[14] Sudaryanto. 1993. Metode dan Teknik Analisis Bahasa. Yogyakarta: Duta Wacana University Press.

[15] Surbakti, Bujur, dkk. 1987. Struktur Bahasa Karo. Jakarta: Pusat Pembinaan dan Pengembangan Bahasa.

[16] Swadesh, Morris. 1975. The Origin an Deriversication of Language. London: Routledge 